\author{
G. M. Eastwood \\ R. Bellomo
}

\section{Comments on Efendijev et al.: Temporal trends in cardiac arrest incidence and outcome in Finnish intensive care units from 2003 to 2013}

Accepted: 10 December 2014

Published online: 23 January 2015

(C) Springer-Verlag Berlin Heidelberg and ESICM 2015

A reply to this comment is available at doi: 10.1007/s00134-014-3643-7.

Dear Editor,

In their retrospective cohort study, Dr. Efendijev and colleagues [1] report a decrease in the incidence of intensive care unit cardiac arrest (ICU-CA) in Finnish ICUs between 2003 and 2013. Strikingly, these investigators report a high crude incidence of 29 in-ICU cardiac arrests/1,000 ICU admissions. The authors suggested that the decreased ICU-CA incidence rate was attributable to technical developments, more effective treatments and reflects a similar reduction in overall hospital mortality over time. However, we are concerned that the findings may not represent worldwide trends in ICUCA or even represent advancements in technology and treatment.

Recently, we reported an ICUCA incidence rate of $6.28 / 1,000$ ICU admissions for patients admitted to an Australian tertiary ICU [2]. This represents a fivefold decrease compared to the Finnish cohort [1]. Furthermore, two previous large single-centre retrospective studies have reported even lower rates of ICU-CA, at 4.02/1,000 admissions [3] and 4.44/1,000 admissions [4], respectively. Together these findings suggest that lower ICU-CA incidence rates may be more closely aligned to healthcare system differences and more proactive decisions about "not for resuscitation" orders, as well as improvements in medical practice, critical care nursing education levels and nurse to patient ratios.

\section{References}

1. Efendijev I, Rag R, Reinikainen M, Hoppu S, Skrivars MB (2014) Temporal trends in cardiac arrest incidence and outcome in Finnish intensive care units from 2003 to 2013. Intensive Care Med 40:1853-1861. doi:10.1007/s00134-014-3509-z

2. Rozen TH, Mullane S, Kaufman M et al (2014) Antecedents to cardiac arrests in a teaching hospital intensive care unit. Resuscitation 85:411-417

3. Galhorta S, DeVita MA, Simmons RL et al (2007) Mature rapid response system and potentially avoidable cardiopulmonary arrests in hospital. Qual Saf Health Care 16:260-265

4. Chan P, Khalid A, Longmore LS et al (2008) Hospital-wide code rates and mortality before and after implementation of a rapid response team. JAMA 21:2506-2513

G. M. Eastwood (匹) - R. Bellomo Department of Intensive Care, Austin Hospital, Melbourne, Australia e-mail: glenn.eastwood@austin.org.au 